\title{
Study of Vitamin D Receptor (VDR) Gene Polymorphisms among Egyptian Cohort Patients with Different Stages of Colorectal Cancer
}

\author{
Mohamed M. Rizk ${ }^{1}$, Nermine H. Zakaria ${ }^{1}$, Waleed G. Elshazely ${ }^{2}$ \\ ${ }^{1}$ Clinical Pathology Department, Faculty of Medicine, Alexandria University, Alexandria, Egypt \\ ${ }^{2}$ Colorectal Surgery Department, Faculty of Medicine, Alexandria University, Alexandria, Egypt \\ Email: mrizk1@yahoo.com, ${ }^{*}$ nermohz@hotmail.com
}

Received 27 January 2014; revised 23 February 2014; accepted 2 March 2014

Copyright (C) 2014 by authors and Scientific Research Publishing Inc.

This work is licensed under the Creative Commons Attribution International License (CC BY). http://creativecommons.org/licenses/by/4.0/

\section{Abstract}

Colorectal cancer represents the third cancer worldwide. Studies showed that insufficient levels of vitamin D may result in colorectal cancer. Genetic variations in genes controlling vitamin D activity would play a role in determining susceptibility to colorectal cancer. Aim of the work: to study the different genotypes of VDR polymorphisms and detect the association between serum levels of 25(OH)VitD and 1,25(OH)2VitD among sample of Egyptian patients with different stages of colorectal cancer. Methods: Ninety patients (60 with different stages of colorectal cancer and 30 patients with benign pathology of the colon) together with $\mathbf{3 0}$ healthy controls were examined using PCR-RFLP analysis for FokI, ApaI and TaqI polymorphisms. Results: Genotype distribution for ApaI polymorphism showed no statistically significant difference between patients (colorectal cancer and benign) and controls with $p=0.1$. There was no statistically significant difference in FokI polymorphism where $p=0.26$ and genotype distribution for TaqI was also insignificant with $p=$ 0.016. The median serum level of 25(0H)VitD was low in cancer cases compared to the control group and benign cases with $(p<0.001)$. There was no statistically significant difference of median serum level of $1,25(\mathrm{OH}) 2 \mathrm{VitD}$ between benign and cancer cases. There was statistically significant difference of median serum level of 25(OH)VitD and 1,25(OH)2VitD between stage I and stage II with ( $p=0.004)$ and $(p<0.001)$, and between stage I and stage III with $(p=0.001)$ and $(p<$ $0.001)$, but no statistically significant difference between stage II and III with $(p=0.514)$. Conclusions: There is ethnic variability in vitamin $D$ receptor gene polymorphisms. The lack of significant association of the studied gene polymorphism in our population suggests that its association with other functionally known gene polymorphism might have a role in the pathogenesis of colorectal cancer.

\footnotetext{
${ }^{*}$ Corresponding author.
}

How to cite this paper: Rizk, M.M., et al. (2014) Study of Vitamin D Receptor (VDR) Gene Polymorphisms among Egyptian Cohort Patients with Different Stages of Colorectal Cancer. Journal of Cancer Therapy, 5, 253-263. 
Keywords

Vitamin D Receptor (VDR); Colorectal Cancer (CRC); PCR-RFLP (Polymorphism)

\section{Introduction}

Colorectal cancer represents the third most common cancer worldwide, second to lung and gastric cancers [1]. Furthermore, it is estimated that there are more than 370,000 cases of colon and rectal cancer diagnosed in Europe every year, with 200,000 cases resulting in death. However, the underlying etiology of colorectal cancer, including cancerous growth of the colon, rectum, and appendix, remains poorly understood. It has been proposed that some categories of external agents, including physical, chemical, and biological carcinogens, may contribute to the development of this disease, and the role of these factors in carcinogenesis would depend largely on genetic factors. Correspondingly, a recent study showed that insufficient levels of vitamin D may result in colorectal cancer [2]. The relevance of vitamin D receptor (VDR) gene restriction fragment length polymorphisms for various types of cancer has been investigated by a great number of studies. It has been hypothesized that VDR polymorphisms may influence both the risk of cancer occurrence and prognosis. Furthermore, genetic variations in genes controlling vitamin $\mathrm{D}$ activity would be hypothesized to play an important role in determining susceptibility to colorectal cancer.

In vivo, vitamin $\mathrm{D}$ helps bones and muscles grow, and may also help prevent many diseases, such as prostate cancer and breast cancer. The biological activity of vitamin D is mediated by the vitamin D receptor (VDR) [3]; which interacts with other cell signaling pathways to influence cell behavior. Expression of VDR has been detected in various organs and tissues of the human body, including the kidney and bone cells. VDR is expressed in normal colonic mucosa; where it plays an important role in regulating cell proliferation, differentiation, and the induction of apoptosis. Furthermore, VDR may be associated with the effects of calcium on colorectal epithelial proliferation [4].

Polymorphisms in VDR have been studied extensively in studies of CRC [5]. These studies have mostly focused on a few selected variants, including the FokI, TaqI, BsmI, and ApaI. Overall, the results have been mixed for studies of individual variants in CRC. Several studies have suggested that haplotypes of these selected variants are associated with risk of CRC and that the association with these variants may be modified by dietary factors, physical activity and BMI. VDR contains several common gene polymorphisms, including a FokI restriction site polymorphism (F/f)in exon II of the 5' region of the gene. This polymorphism in human VDR results in two allelic isoforms of differing length (f/M1 and F/M4). Differential carriage of the isoforms is thought to impact VDR transcriptional activity and vitamin D hormone related disease risk; When bound to VDR, 1,25 dihydroxyvitamin $\mathrm{D} 3$, the active hormonal metabolite of vitamin $\mathrm{D}$, activates target genes via vitamin $\mathrm{D}$ responsive element (VDREs). Classic VDR target genes involved in bone mineral homeostasis include CYP24A1, osteopontin and parathyroid hormone. In addition to its role in bone mineral metabolism, VDR mediates neoclassical actions in the differentiation, proliferation, cell cycle regulation and apoptosis of a number of cell types including the colonic epithelium. Molecular epidemiological studies have shown that polymorphisms in the VDR gene may be linked to biological functions of vitamin D. At the 5' end of the VDR gene, a FokI polymorphism has been associated with a frame shift in the VDR protein [5]. Moreover, polymorphisms in the 3' untranslated region (UTR), including ApaI and TaqI sites, have been shown to influence gene transcription and mRNA stability [6]. Given that polymorphisms in the VDR gene could potentially influence the binding of 1,25(OH) 2D3 and the anti-proliferative effects of vitamin D, VDR polymorphisms have been hypothesized to be associated with colorectal cancer risk. A number of studies have investigated whether VDR gene polymorphisms could be a risk factor for the development of colorectal cancer in different populations.

\section{Aim of the Work}

Study the different genotypes of VDR polymorphisms and detect the association between serum levels of 25(OH)VitD and 1,25(OH)2VitD among sample of Egyptian patients with different stages of colorectal cancer. Methods: Ninty patients (60 with different stages of colorectal cancer and 30 patients with benign pathology of the colon) together with 30 healthy controls were examined using PCR-RFLP analysis for FokI, ApaI and TaqI 
polymorphisms

\section{Patients and Methods}

A total of 90 patients (60 patients with different stages of colorectal cancer included 44 males and 16 females, with age ranged from $40-70$ years, with a mean of $54.13 \pm 7.45$ and 30 cases with benign pathology of the colon, including adenoma, ulcerative colitis, diverticulosis and Crohn's disease) were recruited from Colorectal Unit, General Surgery Department, Main Alexandria University Hospital, Egypt. The control group comprised of 30 healthy subjects matched for age and sex. All patients and controls underwent complete history, clinical examination and laboratory investigations after signing an informed consent and taking the ethical approval from the ethical committee of Alexandria Faculty of Medicine.

\subsection{Measurement of Serum Level of Vitamin D}

For 1,25(OH)2VD, it was measured utilizing a competitive Enzyme-Immuno-Assay (EIA) technique with a selected monoclonal antibody recognizing 1,25 dihydroxy vitamin D. Measuring level of 25(OH)VD was done by ADVIA Centaur using chemiluminescent reaction.

\subsection{VDR Gene Polymorphisms Analysis}

Three polymorphisms were studied: FokI, ApaI and TaqI polymorphism of the VDR gene. DNA extraction was carried out using a commercial kit (QIAamp DNA Mini Kit).

\subsection{FokI Polymorphism of VDR Gene}

It was determined by PCR amplification followed by enzymatic digestion of the products with FokI derived from Fermentas, Lithuania (PCR-RFLP). A region of the receptor gene carrying the reported polymorphic restriction site FokI was amplified by PCR. The specific primers for the VDR were Forward 5"GAT GCC AGC TGG CCC TGG CAC TG “3 and Reverse: 5”ATG GAA ACA CCT TGC TTC TTC TCC CTC”3. For each reaction we added to PCR bead contained in $2 \mathrm{ml}$ sterile tube; $1 \mu \mathrm{l}$ forward primer, $1 \mu \mathrm{l}$ reverse primer, $5 \mu \mathrm{l}$ DNA, $8 \mu \mathrm{l}$ distilled water and $10 \mu \mathrm{l}$ Master Mix. The PCR condition in the thermal cycler was as follow: initial denaturation of $4 \mathrm{~min}$ at $94^{\circ} \mathrm{C}$, followed by 30 cycles of $94^{\circ} \mathrm{C}$ for $1 \mathrm{~min}$, annealing at $60^{\circ} \mathrm{C}$ for $1 \mathrm{~min}$ and extension at $72^{\circ} \mathrm{C}$ for $1 \mathrm{~min}$. A final extension step at $72^{\circ} \mathrm{C}$ for 4 min was also performed. The PCR product was verified using a $2 \%$ agarose gel containing ethidium bromide. PCR products were digested with FokI restriction enzyme (2 $\mathrm{u} / \mathrm{ml}$ ) at $37^{\circ} \mathrm{C}$ for $3 \mathrm{~h}$ followed by electrophoresis in a $2 \%$ agarose gel. The FF genotype (homozygote of common allele) lacks a FokI site and shows only one band of 272 bp. The ff genotype (homozygote of infrequent allele) generates two fragments of 198 and $74 \mathrm{bp}$. The heterozygote displays three fragments of 272,198 and $74 \mathrm{bp}$, designated as Ff (Figure 1, Table 1).

\subsection{ApaI Polymorphism of VDR Gene}

Sets of primers used which were derived from Sigma Aldrich Forward 5'CAA CCA AGA CTA CAA GTA CCG CGT CAG TGA3'.

Reverse 5'CAC TTC GAG CAC AAG GGG CGT TAG C3'. The reaction mixture was then subjected to the following PCR protocol: Initial denaturation of $3 \mathrm{~min}$ at $94^{\circ} \mathrm{C}$. Followed by 35 cycles of $94^{\circ} \mathrm{C}$ for $1 \mathrm{~min}$. An-

Table 1. Distribution of VDR FokI genotype and allele frequency among patients and controls.

\begin{tabular}{|c|c|c|c|c|c|c|}
\hline \multirow[b]{2}{*}{ Group } & \multicolumn{3}{|c|}{ Genotypes } & \multirow[b]{2}{*}{ Number } & \multicolumn{2}{|c|}{ Alleles } \\
\hline & FF & Ff & ff & & $\mathrm{F}$ & $\mathrm{f}$ \\
\hline Patients & $44(49 \%)$ & $37(41 \%)$ & $9(10 \%)$ & 90 & & \\
\hline Cancer colon & $28(46.6 \%)$ & $24(40 \%)$ & $8(13.4 \%)$ & 60 & 125(69\%) & $55(31 \%)$ \\
\hline benign cases & $16(53.3 \%)$ & 13(43.3\%) & $3(3.4 \%)$ & 30 & & \\
\hline Controls & $10(33 \%)$ & $16(54 \%)$ & $4(13 \%)$ & 30 & $36(60 \%)$ & $24(40 \%)$ \\
\hline
\end{tabular}




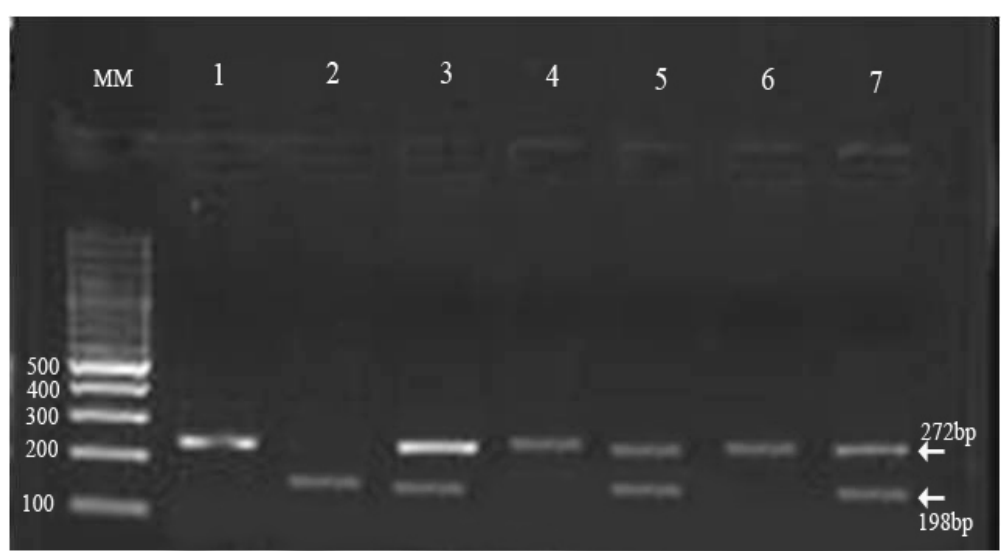

Figure 1. FokI RFLP of VDR gene Lane 1, 4, 6 show FF genotype, Lane 2 show ff genotype, Lane 3, 5, 7 show Ff genotype.

nealing at $61^{\circ} \mathrm{C}$ for $1 \mathrm{~min}$ and extension at $72^{\circ} \mathrm{C}$ for $1 \mathrm{~min}$. A final extension step at $72^{\circ} \mathrm{C}$ for $7 \mathrm{~min}$ was also performed. The PCR product was digested using ApaI restriction enzyme (2 $\mu \mathrm{l} / \mathrm{ml})$ (MBI Fermentas, Lithuania) at $37^{\circ} \mathrm{C}$ for $3 \mathrm{~h}$ followed by electrophoresis in a $2 \%$ agarose gel. The AA genotype (homozygote of common allele) lacks an ApaI site and shows only one band of $2000 \mathrm{bp}$. The aa genotype (homozygote of infrequent allele) generates two fragments of 1700 and $300 \mathrm{bp}$. The heterozygote displays three fragments of 2000, 1700, $300 \mathrm{bp}$, designated as Aa (Figure 2, Table 2).

\subsection{TaqI Polymorphism among VDR}

Using the primer set forward primer 5'CAG AGC ATG GAC AGG GAG CAA G3'; reverse 5'GCA ACT CCT CAT GGG CTG AGG TCT CA3'; using thermocycler program of $94^{\circ} \mathrm{C}$ initial denaturation for 4 min followed by 5 cycles of $94^{\circ} \mathrm{C}$ for $45 \mathrm{sec}, 64^{\circ} \mathrm{C}$ for $60 \mathrm{sec}$ and $72^{\circ} \mathrm{C}$ for $2 \mathrm{~min}$; and a further 25 cycles of $94^{\circ} \mathrm{C}$ for $30 \mathrm{sec}$, $64^{\circ} \mathrm{C}$ for $30 \mathrm{sec}$ and $72^{\circ} \mathrm{C}$ for $45 \mathrm{sec}$. Following amplification, PCR products were digested with Taq I ( $2 \mathrm{U}$ at $65^{\circ} \mathrm{C}$ ) and electrophoresed on $2 \%$ agarose gels stained with ethidium bromide.; giving rise to TT (490, $245 \mathrm{bp}$ ), $\mathrm{Tt}$ (490, 290, 245, $205 \mathrm{bp})$ or tt (290, 245, 205 bp) for Taq I polymorphism (dominant alleles denoting absence of restriction site) (Figure 3, Table 3).

\subsection{Statistical Analysis}

Data were fed to the computer using the Predictive Analytics Software (PASW Statistics 18). Qualitative data were described using number and percent. Association between categorical variables was tested using Chisquare test. When more than $20 \%$ of the cells have expected count less than 5 , correction for chi-square was conducted using Firsher's exact test or Monte Carlo correction. Hardy Weinberg equilibrium was assessed on the sample. Significance of the obtained results was judged at the $5 \%$ level.

\section{Results}

In cancer cases; there were 38 cases (63.3\%) diagnosed as cancer rectum and 22 cases (36.6\%) diagnosed as cancer colon .In benign cases; there were 14 cases (46.7\%) diagnosed as adenoma, 8 cases (26.7\%) as ulcerative colitis, 4 cases (13.3\%) as Crohn's disease and the last 4 cases (13.3\%) as diverticulosis (Table 4).

According to pathological examination; it was found that in cancer cases: 18 cases (30\%) had moderately differentiated infiltrative adenocarcinoma, 8 cases (13.3\%) had moderately differentiated polypoid adenocarcinoma, 8 cases $(13.3 \%)$ had moderately differentiated ulcerative adenocarcinoma followed by 4 cases $(6.7 \%)$ had well differentiated infiltrative mucinous adenocarcinoma, 4 cases (6.7\%) had well differentiated polypoid adenocarcinoma, 4 cases (6.7\%) had well differentiated ulcerative adenocarcinoma, 4 cases $(6.7 \%)$ had poorly differentiated infiltrative adenocarcinoma, 4 cases $(6,7)$ had moderately differentiated infiltrative mucinous adenocarcinoma, then two case (3.3\%) had well differentiated annular mucinous adenocarcinoma, two case had poorly differentiated ulcerative adenocarcinoma, and the two cases (3.3\%) had poorly differentiated annular adenocarcinoma. In benign cases there were 30 cases (100.0\%) had benign pathology of the colon. 


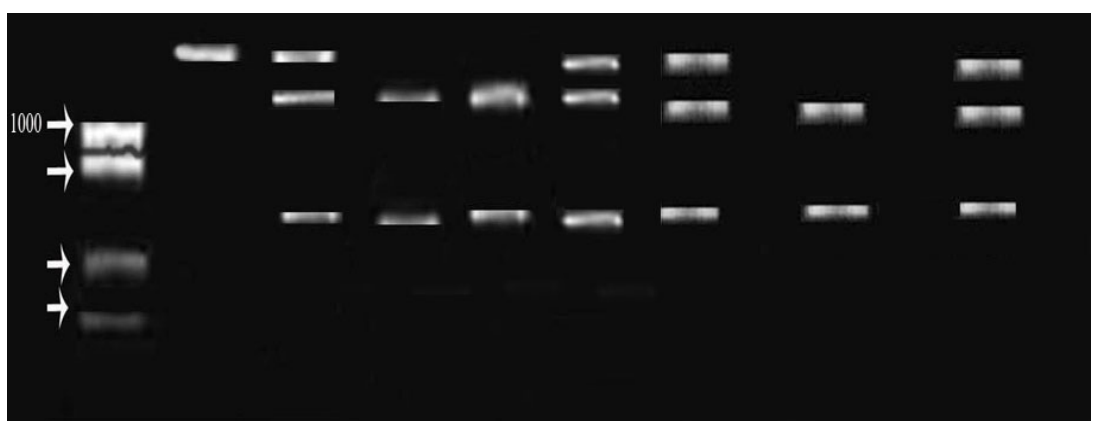

Figure 2. ApaI RFLP of VDR gene, Lane 1: show AA genotype, Lane 3, 4, 7: show aa genotype, Lane 2, 5, 6, 8: show Aa genotype.

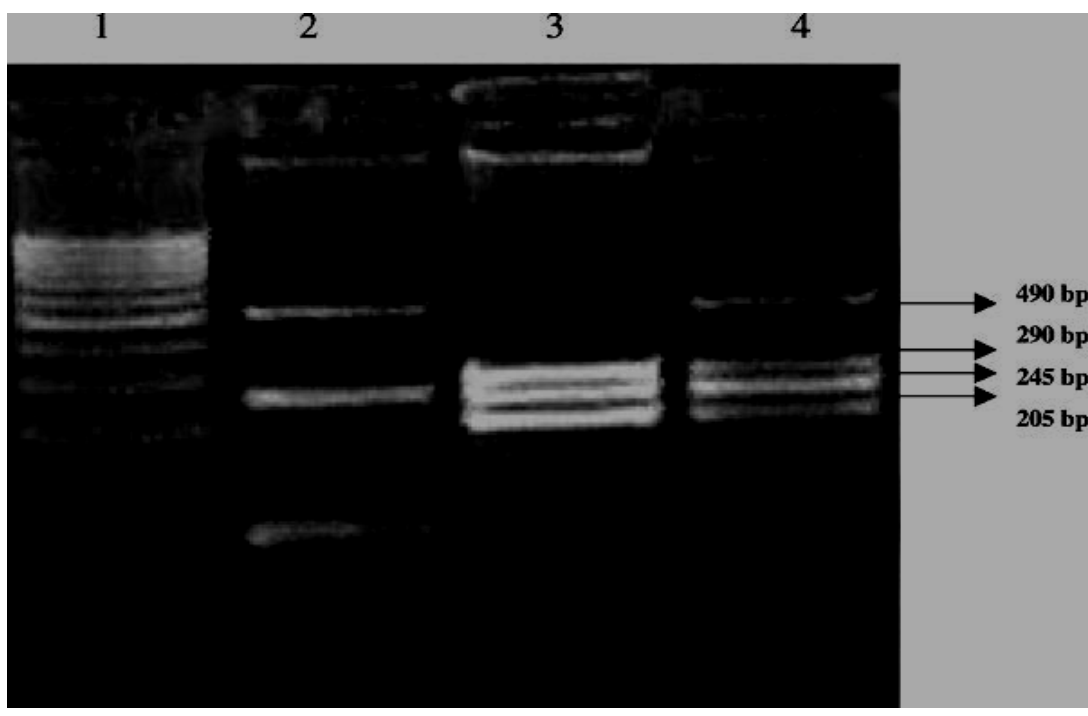

Figure 3. TaqI RFLP of VDR gene, Lane 1: show TT genotype/Lane 3: show tt genotype/Lane 4: show Tt genotype, Relation between TNM staging and vit $\mathrm{D}(1,25$ $(\mathrm{OH}) 2$ vitamin D, 25(OH)vitamin D).

Table 2. Distribution of VDR ApaI genotype and allele frequency among patients and controls.

\begin{tabular}{ccccccc}
\hline & \multicolumn{3}{c}{ Genotypes } & \multicolumn{3}{c}{ Alleles } \\
Group & AA & Aa & aa & Number & A & a \\
\hline Patients & $30(33.5 \%)$ & $50(55.5 \%)$ & $10(11 \%)$ & 90 & & \\
Cancer colon & $20(33 \%)$ & $33(55 \%)$ & $7(12 \%)$ & 60 & $110(62 \%)$ & $70(38 \%)$ \\
benign cases & $10(33 \%)$ & $17(56 \%)$ & $3(11 \%)$ & 30 & & \\
Controls & $7(23 \%)$ & $18(60 \%)$ & $5(17 \%)$ & 30 & $32(53 \%)$ & $28(47 \%)$ \\
\hline
\end{tabular}

Table 3. Distribution of VDR TaqI genotype and allele frequency among patients and controls.

\begin{tabular}{ccccccc}
\hline & \multicolumn{3}{c}{ Genotypes } & \multicolumn{2}{c}{ Alleles } \\
\hline Group & $\mathrm{TT}$ & $\mathrm{Tt}$ & $\mathrm{tt}$ & Number & $\mathrm{T}$ & $\mathrm{t}$ \\
\hline Patients & $24(26 \%)$ & $51(56 \%)$ & $15(18 \%)$ & 90 & & \\
Cancer colon & $16(26 \%)$ & $34(56 \%)$ & $10(18 \%)$ & 60 & $99(55 \%)$ & $81(45 \%)$ \\
benign cases & $8(27 \%)$ & $17(57 \%)$ & $5(16 \%)$ & 30 & & \\
Controls & $14(46.5 \%)$ & $13(43.5 \%)$ & $3(10 \%)$ & 30 & $41(68 \%)$ & $19(32 \%)$ \\
\hline
\end{tabular}




\section{TNM Stage}

In cancer cases there were 18 cases (30\%) with stage I, 16 cases (26.7\%) with stage II and 26 cases (43.3\%) with stage III (Table 5).

Genotype distribution comparison for total patients (cancer + benign cases $)=2.69, \mathrm{p}=0.26$.

Allele distribution comparison for total patients (cancer + benign cases) $=1.52, \mathrm{p}=0218$. Both cases and controls were in Hardy-Weinberg equilibrium $\mathrm{p}=0.577$.

Regarding Fok1 polymorphism; In benign cases: 16 cases (53.3\%) were FF genotype, 13 cases (43.3\%) were Ff genotype, and 3 cases (3.4\%) were ff genotype, in cancer cases: 28 cases (46.6.0\%) were FF genotype, 24 cases $(40.0 \%)$ were Ff genotype, and 8 cases $(13.4 \%)$. In controls: 10 cases (33.3\%) were FF genotype, 16 cases (53.3\%) were Ff genotype, and 4 cases (13.0\%) were ff genotype. Comparing the genotypes between patients and controls no statistical significant difference was observed in the frequencies of Fok1 genotype. The observed and expected genotypic proportions of Fok1 polymorphism was in the Hardy-Weinberg equilibrium in all groups.

Genotype distribution comparison for total patients (cancer + benign cases) $=4.604, \mathrm{p}=0.1$ allele distribution comparison for total patients (cancer + benign cases) $=4.2, \mathrm{p}=0.04$. Both cases and controls were in HardyWeinberg equilibrium with $\mathrm{p}=0.295$.

Regarding ApaI polymorphism; In benign cases: 10 cases (33.3\%) were AA genotype, 17 cases (56\%) were Aa genotype, and 3 cases (11\%) were aa genotype, in cancer cases: 33 cases (55\%) were Aa genotype, 20 cases (33\%) were AA genotype, and 7 cases (12\%) were aa genotype. In control subjects we identified 18 cases (60.0\%) with Aa genotype, 7 cases (23\%) with AA genotype, and 5 cases (17\%) with aa genotype. Comparing the genotypes between patients and controls there was a statistical significant difference observed in the frequencies of ApaI genotype. The observed and expected genotypic proportions of ApaI polymorphism were in the Hardy-Weinberg equilibrium in all groups.

Genotype distribution comparison for total patients (cancer + benign cases) $=8.27, \mathrm{p}=0.016$

Allele distribution comparison for total patients (cancer + benign cases) $=7.22$, p $=00.0072$; both cases and controls were in Hardy-Weinberg equilibrium $\mathrm{p}=0.302$. Regarding TaqI polymorphism; In benign cases: 8 cases (27\%) were TT genotype, 17 cases (57\%) were Tt genotype, and 5 cases (16\%) were tt genotype, in cancer cases: 34 cases (56\%) were Tt genotype, 16 cases (26\%) were TT genotype, and 10 cases (18\%) were tt geno-

Table 4. Comparison between patients groups according to diagnosis.

\begin{tabular}{ccccccc}
\hline Diagnosis & \multicolumn{2}{c}{ Benign cases $(\mathbf{n}=\mathbf{3 0})$} & \multicolumn{2}{c}{ Cancer cases $(\mathbf{n}=\mathbf{6 0})$} & \multicolumn{2}{c}{ Total cases $(\mathbf{n}=\mathbf{9 0})$} \\
& $\mathbf{N o}$ & $\mathbf{\%}$ & $\mathbf{N o}$ & $\mathbf{\%}$ & $\mathbf{N o}$ & $\%$ \\
Cancer rectum & 0 & 0.0 & 38 & 63.3 & 38 & 42.2 \\
Crohn's disease & 4 & 13.3 & 0 & 0.0 & 4 & 4.4 \\
Ulcerative colitis & 8 & 26.7 & 0 & 0.0 & 8 & 8.9 \\
Adenoma & 14 & 46.7 & 0 & 0.0 & 14 & 15.6 \\
Diverticulosis & 4 & 13.3 & 0 & 0.0 & 4 & 4.4 \\
Cancer colon & 0 & 0.0 & 22 & 36.6 & 22 & 24.4 \\
MCp & & $<0.001^{*}$ & & & \\
\hline
\end{tabular}

MCp: p value for Monte Carlo test between benign and cancer; "Statistically significant at $\mathrm{p} \leq 0.05$.

Table 5. Descriptive study of cancer patients according to TNM stage.

\begin{tabular}{ccc}
\hline TNM Stage & $(\mathbf{n = 6 0 )}$ & \% \\
\hline I & 18 & 30.0 \\
II & 16 & 26.7 \\
III & 26 & 43.3 \\
\hline
\end{tabular}


type. In control subjects we identified 13 cases (43.5\%) with Tt genotype, 14 cases (46\%) with TT genotype, and 3 cases (10\%) with tt genotype. Comparing the genotypes between patients and controls there was a statistical significant difference observed in the frequencies of TaqI genotype. The observed and expected genotypic proportions of TaqI polymorphism were in the Hardy-Weinberg equilibrium in all groups.

\section{Relation between TNM Staging and vit D(1,25(OH)2vitamin D, 25(OH)vitamin D)}

It was found that median serum level of 1,25(OH)2vitamin D showed a trend decrease with staging; where stage I of cancer cases was $68.0 \mathrm{pg} / \mathrm{ml}$, of stage II was $40.50 \mathrm{pg} / \mathrm{ml}$, and that of stage III was $24.0 \mathrm{pg} / \mathrm{ml}$.There were statistically significant difference of median serum level of 1,25(OH)2vitamin D between stage I and stage II with ( $p=0.001)$, statistically significant difference of median serum level of $1,25(\mathrm{OH}) 2 \mathrm{vitamin} \mathrm{D}$ between stage I and stage III with ( $\mathrm{p}=<0.001)$, and also between stage II and stage III with ( $\mathrm{p}=<0.001)$.

By relation between median serum level of 25(OH)vitamin D of cancer cases and TNM stage, it was found that median serum level of 25(OH)vitamin D of stage I was $18.50 \mathrm{ng} / \mathrm{ml}$, of stage II was $9.05 \mathrm{ng} / \mathrm{ml}$, and that of stage III was $7.10 \mathrm{ng} / \mathrm{ml}$. There were statistically significant difference of median serum level of 25(OH)vitamin D between stage I and stage II with $(p=0.004)$, and also between stage I and stage III with $(p=0.001)$, but no statistically significant difference between stage II and stage III with ( $\mathrm{p}=0.514)$ (Table 6).

There was no statistical significant difference of mean serum level of 1,25(OH)2VD between benign and cancer cases compared to control group. There was no statistically significant differences between Crohn's disease, ulcerative colitis, adenoma and diverticulosis compared to control group regarding median serum level of $1,25(\mathrm{OH}) 2$ vitamin $\mathrm{D}$ with $(\mathrm{p}=0.073, \mathrm{p}=0.80, \mathrm{p}=0.916$ and $\mathrm{p}=0.296$ respectively). The serum level of $25(\mathrm{OH}) \mathrm{VD}$ was low in cancer cases compared to the serum level of control group, also there were statistically significant lower serum level of $25(\mathrm{OH}) \mathrm{VD}$ of cancer cases compared to benign cases with $(\mathrm{p}=<0.001)$. In relation to benign cases, it was found that median serum level of 25(OH)vitamin D was $22.50 \mathrm{ng} / \mathrm{ml}, 20.50$ $\mathrm{ng} / \mathrm{ml}, 28.0 \mathrm{ng} / \mathrm{ml}$, and $33.0 \mathrm{ng} / \mathrm{ml}$ in Crohn's disease, ulcerative colitis, adenoma and diverticulosis respectively whereas the median serum level in control group was $28.0 \mathrm{ng} / \mathrm{ml}$ (Data not shown).

There was statistically significant difference of serum level of 1,25(OH)2VD between stage I and stage II colorectal cancer with ( $\mathrm{p}=0.001)$, statistically significant difference of serum level of 1,25(OH)2VD between stage I and stage III with ( $\mathrm{p}=<0.001)$, and also between stage II and stage III with ( $\mathrm{p}=<0.001)$. There were statistically significant difference of serum level of $25(\mathrm{OH}) \mathrm{VD}$ between stage I and stage II with (p = $0.004)$, and also between stage I and stage III with $(p=0.001)$, but no statistically significant difference between stage II and stage III with $(\mathrm{p}=0.514)$. Both 1, 25(OH)2VD and 25(OH)VD showed a significant negative

Table 6. Relation between TNM and 1,25(OH)2vitamin D and 25(OH)vitamin D.

\begin{tabular}{|c|c|c|c|c|}
\hline & \multicolumn{3}{|c|}{ TNM Stage } & \multirow{2}{*}{${ }^{\mathrm{KW}} \mathbf{p}$} \\
\hline & I $(\mathbf{n}=18)$ & II (n = 16) & III (n = 26) & \\
\hline \multicolumn{5}{|c|}{ 1,25(OH)2vitamin D pg/ml } \\
\hline Min - Max & $53.0-70.30$ & $36.0-47.0$ & $13.50-29.50$ & \multirow{4}{*}{$<0.001^{*}$} \\
\hline Median & 68.0 & 40.50 & 24.0 & \\
\hline $\mathbf{p}_{1}$ & & $0.001^{*}$ & $<0.001^{*}$ & \\
\hline $\mathbf{p}_{2}$ & & & $<0.001^{*}$ & \\
\hline \multicolumn{5}{|c|}{ 25(OH)vitamin D ng/ml } \\
\hline Min - Max & $10.60-24.10$ & $3.90-17.10$ & $4.10-25.0$ & \multirow{4}{*}{$0.001^{*}$} \\
\hline Median & 18.50 & 9.05 & 7.10 & \\
\hline $\mathbf{p}_{1}$ & & $0.004^{*}$ & $0.001^{*}$ & \\
\hline $\mathbf{p}_{2}$ & & & 0.514 & \\
\hline
\end{tabular}

$\mathrm{p}_{1}$ : $\mathrm{p}$ value for Mann Whitney test between stage I and each other stages; $\mathrm{p}_{2}$ : value for Mann Whitney test between stage II and III; ${ }^{\mathrm{KW}} \mathrm{p}$ : p value for Kruskal Wallis test; ${ }^{*}$ Statistically significant at $\mathrm{p} \leq 0.05$ 
correlation with age of cancer cases ( $p=0.047, \mathrm{r}_{\mathrm{s}}=-0.316, \mathrm{p}=<0.001$, $\mathrm{rs}=-0.644$ and $\mathrm{p}=0.003$, $\mathrm{rs}=-0.531$ ) respectively.

Correlation studies between the different genotypes of the VDR gene and 1.25(OH)2vitamin D level in benign and cancer patients were done. No statistically significant difference was found between the 3 genotypes regarding median level of $1.25(\mathrm{OH}) 2$ vitamin $\mathrm{D}$ of patients for the three polymorphisms.

\section{Discussion}

In the present study, the age and sex distribution among the colorectal cancer cases and controls did not show statistically significant differences where it was homogenously distributed.

There was statistically significant lower serum level of 25(OH)VD of colorectal cancer cases compared to the control group with $(\mathrm{p}<0.001)$, there was no statistically significant difference between benign cases and controls regarding $25(\mathrm{OH}) \mathrm{VD}$ with $(\mathrm{p}=0.288)$. These data were similar to Woolcott et al. [7] who conducted a study and found colorectal cancer risk was inversely associated with plasma 25(OH)D concentration. In this study plasma 25(OH)D was inversely associated with risk of colorectal cancer with $(\mathrm{P}=0.02)$. The benefit was significant for cancers of the rectum and distal colon, whereas there was little evidence that 25(OH)D was associated with a lower cancer risk at the proximal colon. It is plausible that effects may differ for the proximal and distal colorectal sites given differences in their molecular features and in risks associated with genetic and environmental factors.

In this study we selected 30 patients with benign pathology of the colon including fourteen patients with adenoma, eight with ulcerative colitis, four with diverticulosis and four with Crohn's disease. There was no statistically significant difference between Crohn's disease, ulcerative colitis, adenoma and diverticulosis compared to control group regarding median serum level of $1,25(\mathrm{OH}) 2$ vitamin $\mathrm{D}$ with $(\mathrm{p}=0.073, \mathrm{p}=0.80, \mathrm{p}=$ 0.916 and $\mathrm{p}=0.296$ respectively).

Peters et al. [8] who carried out nested case-control study within the Prostate, Lung, Colorectal and Ovarian Cancer Screening (PLCO) trial; observed 73\% reduction in advanced adenoma risk among women with serum 25(OH)D levels in the highest quintile compared with those in the lowest quintile. No association between serum 25(OH)D levels and adenoma risk was observed among men.

In the present work there was no statistically significant difference between benign and cancer cases compared to control group regarding serum level of $1.25(\mathrm{OH}) 2 \mathrm{VD}$ with $(\mathrm{p}=0.868$ and $\mathrm{p}=0.800)$ respectively also there was no statistically significant difference between benign and cancer cases with $\mathrm{p}=0.782$. These data were similar to Jenab [9]. who carried out his cohort study with 121,700 female participants who were ages 30 to 55 years ,in this study $1,25(\mathrm{OH}) 2 \mathrm{D}$ levels were similar in cases and controls for both assay with no association between 1,25(OH)2D and risk of colorectal cancer.

Although 1,25(OH)D3 is the biologically active form of vitamin D, and, thus, would be thought to be the ideal measure for vitamin D status, it is not. There are several reasons for this. The circulating half life of circulating $1,25(\mathrm{OH}) 2 \mathrm{D}$ is only $4-6$ hours. Circulating levels of $1,25-(\mathrm{OH})_{2}-\mathrm{D}$ are a thousand fold less than 25-OH-D. As a participants who were ages 30 to 55 years ,in this study $1,25(\mathrm{OH}) 2 \mathrm{D}$ levels were similar in cases and controls for both assay years with no association between 1,25(OH)2D and risk of colorectal cancer.

Patient becomes vitamin D deficient; there is a decrease in intestinal calcium absorption which lowers ionized calcium transiently. This signal is recognized by the calcium sensor in the parathyroid glands to increase the production and secretion of PTH [10]. PTH regulates calcium metabolism by increasing tubular reabsorption of calcium in the kidney, increasing mobilization of calcium from the skeleton and by increasing the renal production of 1,25-(OH $)_{2}-\mathrm{D}$ [11]. Thus, as a patient becomes vitamin D insufficient and deficient, the increase in PTH levels result in normal or elevated levels of $1,25-(\mathrm{OH})_{2}-\mathrm{D}$. This makes the $1,25-(\mathrm{OH})_{2}-\mathrm{D}$ assay useless as a measure of vitamin D status. 25-OH-D is the only vitamin D metabolite that is used to determine whether a patient is vitamin $\mathrm{D}$ deficient, sufficient or intoxicated. 25(OH)D is the major circulating form of vitamin $\mathrm{D}$ that has a half life of approximately 2-3 weeks. 25-OH-D is a summation of both vitamin D intake and vitamin D that is produced from sun exposure.

Several polymorphisms have been identified in VDR gene FokI, TaqI, and ApaI. The following genotypic frequency was obtained for the FokI as for patients group the highest prevalence for FF was 49\% (44) while for $\mathrm{Ff}$, and ff the percentage was as follow $41.0 \%$ (37) and $10 \%$ (9) respectively. While the control group the highest prevalence for Ff was 53.3\% (16), while for FF, and ff the percentage was as follow 33.3\% (10) and 13.3\% (4) 
respectively. While that for the TaqI the frequency for TT was 26\% (24) while for Tt, and tt was as followed $56.0 \%$ (51) and 18\% (15) respectively. While the control group the highest frequency for Tt was 43.5\% (13), while for TT and tt the percentage was as follow 46.5\% (14) and 10\% (3) respectively.

For the ApaI the frequency for AA was 33.5\% (30) while for Aa, and aa was as follow 55.5\% (50) and 11\% (10) respectively. While the control group the highest frequency for Aa was $60 \%$ (18), while for AA, and aa the percentage was as follow $23 \%$ (7) and $17 \%$ (5) respectively.

The frequency of the polymorphisms is dependent on ethnicity and vary between our population and Caucasians, but also vary from other Asian countries like Japan [12] (FF-37\%, Ff-51\%, ff-12\% and TT-77\%, $\mathrm{Tt}-22 \%, \mathrm{tt}-1 \%$ respectively). The frequency of the FokI and TaqI genotypes in the present study also shows different results than that of a study conducted in North Indian population (FF-44\%, Ff $-49 \%$, ff $-7 \%$ and $\mathrm{TT}-49 \%, \mathrm{Tt}-40 \%, \mathrm{tt}-11 \%$ respectively) [13]. Most data indicate that the $\mathrm{F}$ allele is more effective than the $\mathrm{f}$ allele in trans-activation of the 1,25(OH)2-D3 signal [14] Indians have lower bone density as compared to the North American and European counterparts and differences in the frequency of genetic variants may be a contributing factor. Thus the current data signifies an impact of ethnicity and provides a basis for future epidemiological and clinical studies.

Jenab et al. [15] who carried out his study on a total of 1,248 first incident CRC cases (number of colon cancer, 785; number of rectal cancer, 463), the highest prevelance was for Ff 493 cases while for FF was 414 cases, and for ff was 170 cases. While the control group was 518 cases for Ff, 402 cases for FF, and 157 cases for ff. There was no meaningful or statistically significant cancer risk associations were noted for either the VDR Fok1. The observed and expected genotypic proportions of Fok1 polymorphism was in the HardyWeinberg equilibrium in both groups.

Mahmoudi et al. [16] who carried out his study on CRC cases (age range, 16 - 86 years) and 452 healthy subjects (age range, 13 - 90 years) as a control. In colorectal cancer patients: 246 cases were FF, 186 cases were Ff, and 20 cases were ff, while in control group: 253 were FF, 175 were Ff, and 24 were ff. The results of this study suggest that FokI polymorphism of the VDR gene is not associated with susceptibility to CRC.

In the present study there was statistically significant difference of mean serum level of 25(OH)VD between stage I and stage II with ( $p=0.004)$, and also between stage I and stage III with $(\mathrm{p}=0.001)$, but no statistically significant difference between stage II and stage III with ( $\mathrm{p}=0.514)$, also there were statistically significant difference of mean serum level of 1,25(OH)VD between stage I and stage II with ( $p=0.001)$, statistically significant difference of mean serum level of 1,25(OH)VD between stage I and stage III with $(\mathrm{p}=<0.001)$, and also between stage II and stage III with ( $\mathrm{p}=<0.001)$.

It was found that CRC cell responsiveness to 1,25(OH)2D3 depends mainly on the expression of VDR and on the bioavailability of 1,25(OH)2D3 within the cell. The intracellular level of 1,25(OH)2D3 is determined by the circulating levels of 25(OH)D3 and 1,25(OH)2D3, and by the activity of CYP27B1 and CYP24A1 within the cell. CYP27B1 expression and activity are up-regulated at early stages of colorectal tumourigenesis and drastically decreased in advanced CRC, while those of CYP24A1 are elevated in colorectal carcinomas. These changes lead to attenuated 1,25(OH)2D3 synthesis and accelerated 1,25(OH)2D3 catabolism in advanced CRC, causing resistance to $1,25(\mathrm{OH}) 2 \mathrm{D} 3$.

Many studies have investigated individual VDR polymorphisms in isolation when assessing the Association with different disease states, but these results are often non significant [17]. However a small number of studies such as in this study have carried out cross-genotyping analysis on the VDR polymorphisms and have found that this can reveal a positive association with disease status. Guy et al. [18] reported that FokI genotype did modulate the increased risk associated with bb/LL genotype such that possession of one or more $\mathrm{F}$ alleles together with the bb/LL genotype augmented breast cancer risk.

To our knowledge, there are only a few reports investigating a combination of TaqI and FokI Genotypes of VDR in colorectal cancer. One of the studies by Bodiwala et al. [19] reported that the FFTT combined genotype was associated with reduced prostate cancer risk in the presence of the main effects. In this present study, our results showed that $30.8 \%$ of controls and $3.8 \%$ of colorectal patients have genotype TfFf. In conclusion, our results suggested that the VDR TaqI and FokI polymorphisms may be important modifiers of individual colorectal cancer risk among Turkish patients. Additional investigations into how different genotypes may affect the functional mechanisms of the VDR will provide a better strategy for identifying subjects at risk of colorectal cancer and for developing improved treatments.

However, the results are inconsistent. Since it can be difficult for individual studies to achieve, sufficient 
statistical power to detect associations between VDR polymorphisms and colorectal cancer risk, a Meta analysis that combines data from all published studies may detect genetic associations more accurately. In addition, a reduced probability of false-negatives might also be achieved. Therefore, a systematic meta-analysis of population-based studies was performed to investigate the association between VDR polymorphisms and the risk of colorectal cancer. Based on the search strategy and criteria used, 23 studies were analyzed which identified several important polymorphic variants. Different geographical latitudes of the Japanese, Canadian and Australian populations could be a factor influencing the differences in ApaI and TaqI data obtained from each study. Furthermore, the association of certain polymorphism with certain disease does not necessarily mean that the polymorphism causes it. What seems to be clear also is that, the influence of polymorphisms may not be related to changes in the protein structure, but to differences in stability and or translation efficiency of the RNA, or even to changes in a totally different gene .Accordingly, the VDRL would act as a marker of truly functional polymorphism elsewhere. It is also likely that the difference in race, diet or latitude could alter the influence of polymorphism on the susceptibility to diseases diluting the effects observed in other populations.

Further studies are needed to understand the molecular and cellular variations affected by the polymorphisms on large scales, taking into considerations the contribution of the environmental factors. Moreover the study of different haplotypes could be more useful than single gene polymorphism in order to better understand the role in carcinogenesis.

\section{References}

[1] World Health Organization (2012) Cancer. Fact Sheet No. 297.

[2] Garland, C.F. and Garland, F.C. (1980) Do Sunlight and Vitamin D Reduce the Likelihood of Colon Cancer? International Journal of Epidemiology, 9, 227-231. http://dx.doi.org/10.1093/ije/9.3.227

[3] Garland, C.F., Garland, F.C. and Gorham, E.D. (1999) Calcium and Vitamin D. Their Potential Roles in Colon and Breast Cancer Prevention. Annals of the New York Academy of Sciences, 889, 107-119. http://dx.doi.org/10.1111/j.1749-6632.1999.tb08728.x

[4] Holt, P.R. (1999) Dairy Foods and Prevention of Colon Cancer: Human Studies. The Journal of the American College of Nutrition, 18, 379S-391S. http://dx.doi.org/10.1080/07315724.1999.10718902

[5] Miyamoto, K., Kesterson, R.A., Yamamoto, H., Taketani, Y., Nishiwaki, E., Tatsumi, S., Inoue, Y., Morita, K., Takeda, E. and Pike, J.W. (1997) Structural Organization of the Human Vitamin D Receptor Chromosomal Gene and Its Promoter. Molecular Endocrinology, 11, 1165-1179. http://dx.doi.org/10.1210/mend.11.8.9951

[6] Whitfield, G.K., Remus, L.S., Jurutka, P.W., Zitzer, H., Oza, A.K., Dang, H.T., Haussler, C.A., Galligan, M.A., Thatcher, M.L., Encinas Dominguez, C. and Haussler, M.R. (2001) Functionally Relevant Polymorphisms in the Human Nuclear Vitamin D Receptor Gene. Molecular and Cellular Endocrinology, 177, 145-159. http://dx.doi.org/10.1016/S0303-7207(01)00406-3

[7] Woolcott, C.G., Wilkens, L.R., Nomura, A.M.Y., et al. (2010) Plasma 25-Hydroxyvitamin D Levels and the Risk of Colorectal Cancer: The Multiethnic Cohort Study. Cancer Epidemiology, Biomarkers \& Prevention, 19, 130-134. http://dx.doi.org/10.1158/1055-9965.EPI-09-0475

[8] Ulrike, P. (2004) Circulating Vitamin D Metabolites, Polymorphism in Vitamin D Receptor and Colorectal Adenoma Risk. Cancer Epidemiology, Biomarkers \& Prevention, 13, 546-555.

[9] Jenab, M. (2010) Association between Pre-Diagnostic Circulating Vitamin D Concentration and Risk of Colorectal Cancer in European Populations: A Nested Case-Control Study. BMJ, 340, b5500. http://dx.doi.org/10.1136/bmj.b5500

[10] Holick, M.F. (2009) Vitamin D Status: Measurement, Interpretation and Clinical Application. Annals of Epidemiology, 19, 73-78. http://dx.doi.org/10.1016/j.annepidem.2007.12.001

[11] Holick, M.F. (2006) High Prevalence of Vitamin D Inadequacy and Implications for Health. Mayo Clinic Proceedings, 81, 353-373. http://dx.doi.org/10.4065/81.3.353

[12] Minamitani, K., Takahashi, Y., Mingawa, M., Yasuda, T. and Niimi, H. (1998) Difference in Height Associated with a Translation Start Site Polymorphism in the Vitamin D Receptor Gene. Pediatric Research, 44, 628-632. http://dx.doi.org/10.1203/00006450-199811000-00002

[13] Bid, H.K., Mishra, D.K. and Mittal, R.D. (2005) Vitamin-D Receptor (VDR) Gene (Fok-I, Taq-I and Apa-I) Polymorphisms in Healthy Individuals from North Indian Population. Asian Pacific Journal of Cancer Prevention, 6, 147-152.

[14] Whitfield, G.K., Remus, L.S., Jurutka, P.W., Zitzer, H., Oza, A.K., Dang, H.T., et al. (2001) Functionally Relevant Polymorphisms in the Human Nuclear Vitamin D Receptor Gene. Molecular and Cellular Endocrinology, 177, 145- 
159. http://dx.doi.org/10.1016/S0303-7207(01)00406-3

[15] Jenab, M. and McKay, J. (2009) Vitamin D Receptor and Calcium Sensing Receptor Polymorphisms and the Risk of Colorectal Cancer in European Populations. Cancer Epidemiology, Biomarkers \& Prevention, 18, 2485-2491. http://dx.doi.org/10.1158/1055-9965.EPI-09-0319

[16] Mahmoudi, T., Karimi, K. and Mohebbi, S.R. (2011) Start Codon FokI and Intron 8 BsmI Variants in the Vitamin D Receptor Gene and Susceptibility to Colorectal Cancer. Molecular Biology Reports, 38, 4765-4770. http://dx.doi.org/10.1007/s11033-010-0613-1

[17] Zmuda, J.M., Cauley, J.A. and Ferrel, R.E. (2000) Molecular Epidemiology of Vitamin D Receptor Gene Variants. Epidemiologic Reviews, 22, 203-217. http://dx.doi.org/10.1093/oxfordjournals.epirev.a018033

[18] Guy, M., Lowe, L.C., Bretherton-Watt, D., et al. (2004) Vitamin D Receptor Gene Polymorphism and Breast Cancer risk. Clinical Cancer Research, 15, 5472-5481. http://dx.doi.org/10.1158/1078-0432.CCR-04-0206

[19] Bodiwala, D., Luscombe, C.J., French, M.E., et al. (2004) Polymorphism in the Vitamin D Receptor Gene, Ultraviolet Radiation, and Susceptibility to Prostate Cancer. Environmental and Molecular Mutagenesis, 43, 121-127.

http://dx.doi.org/10.1002/em.20000 